UCRL-JC-123478

PREPRINT

\title{
RESORCINOL-FORMALDEHYDE AND CARBON AEROGEL MICROSPHERES
}

C.T. Alviso

R.W. Pekela

J. Gross

Lawrence Livermore National Laboratory

X. Lu

R. Caps

J. Fricke

Physikalisches Institut, Wurzburg, Germany

This paper was prepared for submittal to

Materials Research Society, 1996 Spring Meeting

in San Francisco, CA on April 8-12, 1996.

April 1996

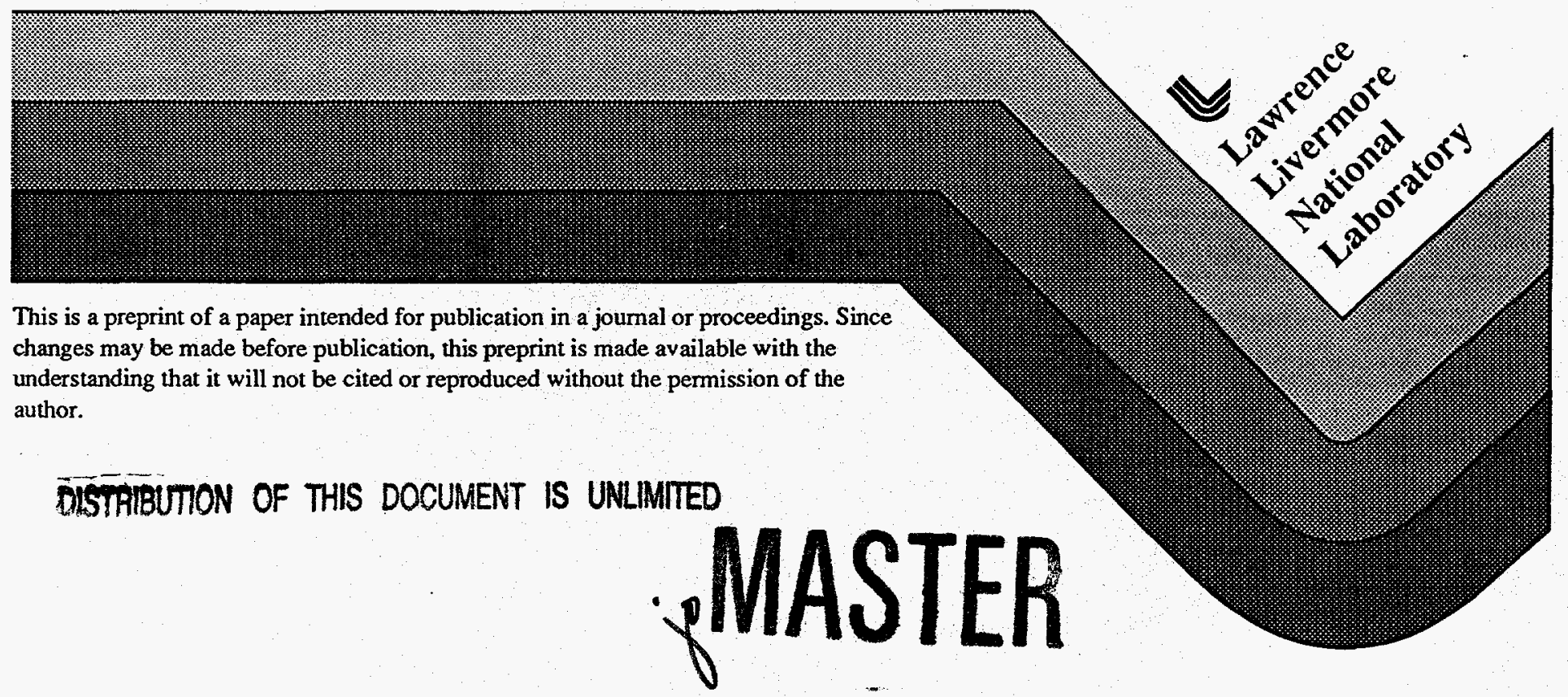




\section{DISCLAMMER}

Portions of this document may be illegible in electronic image products. Images are produced from the best available original document. 


\section{DISCLAIMER}

This report was prepared as an account of work sponsored by an agency of the United States Government. Neither the United States Government nor any agency thereof, nor any of their employees, makes any warranty, express or implied, or assumes any legal liability or responsibility for the accuracy, completeness, or usefulness of any information, apparatus, product, or process disciosed, or represents that its use would not infringe privately owned rights. Reference herein to any specific commercial product, process, or service by trade name, trademark, manufacturer, or otherwise does not necessarily constitute or imply its endorsement, recommendation, or favoring by the United States Government or any agency thereof. The views and opinions of authors expressed herein do not necessarily state or reflect those of the United States Government or any agency thereof. 


\title{
RESORCINOL-FORMALDEHYDE AND CARBON AEROGEL MICROSPHERES
}

\author{
C.T. ALVISO, R.W. PEKALA, J. GROSS, X. LU*, R. CAPS*, AND J. FRICKE* \\ Chemistry and Materials Science Directorate \\ Lawrence Livemore National Laboratory \\ Livermore, CA 94550 \\ *Physikalisches Institut, \\ Universität, Am Hubland, \\ 97074 Würzburg, Germany
}

\begin{abstract}
Aerogels are a unique class of materials possessing an open-cell structure with ultrafine cells/pores $(<100 \mathrm{~nm})$, high surface area $\left(400-1100 \mathrm{~m}^{2} / \mathrm{g}\right)$, and a solid matrix composed of interconnected particles, fibers, or platelets with characteristic dimensions of $10 \mathrm{~nm}$. Although monolithic aerogels are ideal candidates for many applications (e.g. transparent window insulation), current processing methods have limited their introduction into the commercial marketplace. Our research focuses on the formation of resorcinol-formaldehyde (RF) aerogel microspheres which offer an attractive alternative to monolith production. An inverse emulsion polymerization is used to produce these spherical gel particles which undergo solvent exchange followed by supercritical drying with carbon dioxide. This process yields aerogel microspheres (10-80 $\mu$ diameter) which can be used as loosely packed powders, compression molded into nearnet shapes using a polymer binder, or used as additives in conventional foaming operations to produce new aerogel composites with superior thermal properties. The emulsification procedure, thermal characterization, mechanical properties, and potential applications of RF aerogel microspheres will be discussed.
\end{abstract}

\section{INTRODUCTION}

Resorcinol-formaldehyde (RF) may very well be considered the "grandfather" of organic aerogels. Developed almost a decade ago, this material is produced from the aqueous polycondensation of resorcinol (1,3-dihydroxybenzene) with formaldehyde. The resultant crosslinked gels are dark red in color and transparent. Supercritical drying gives resorcinolformaldehyde aerogels with small cell/pore size, high surface area, and low thermal conductivity. Because RF aerogels are composed of a highly crosslinked aromatic polymer, they can be pyrolyzed in an inert atmosphere to form vitreous carbon. Although several organic reactions that proceed through a sol-gel transition have been identified at LLNL, resorcinol-formaldehyde is the most widely studied[1-6].

The structure and properties of organic aerogels are analogous to their inorganic counterparts. These materials have continuous porosity, an ultrafine cell/pore size $(\leq 100 \mathrm{~nm})$, high surface area $\left(400-1100 \mathrm{~m}^{2} / \mathrm{g}\right)$, and a solid matrix composed of interconnected colloidal-like particles, fibrous chains, or platelets with characteristic diameters of $10 \mathrm{~nm}$. This nanostructure is responsible for the unique thermal, acoustic, optical, electrical, and mechanical properties of aerogels [7,8].

A major advantage of organic aerogels is their low $Z$ (atomic number) composition. In general, most polymers have lower thermal conductivities than inorganic glasses. This same trend would be expected for aerogels having such compositions. Under ambient conditions, resorcinolformaldehyde aerogels are better thermal insulators than silica aerogels. Monolithic RF aerogels have obtained a record low thermal conductivity of $0.012 \mathrm{~W} / \mathrm{m} \cdot \mathrm{K}$, while silica aerogels have a minimum value of $0.016 \mathrm{~W} / \mathrm{m} \cdot \mathrm{K}$. These data demonstrate the importance of controlling both the composition and structure of aerogels [7-9].

Although monolithic aerogels are ideal candidates for many applications, the shape and size of the final product is limited to that of the commercial processing equipment. The formation of aerogel microspheres offers an attractive alternative to monolith production. Microspheres can be 
produced in a semi-continuous process, can be used as loosely packed powders or as additives in conventional foaming operations to produce new aerogel composites with superior acoustic and thermal properties [7].

\section{EXPERIMENTAL}

An inverse emulsion process was used to produce RF aerogel microspheres. Resorcinol $(99+\%$; Aldrich Chemical Co.) and formaldehyde (37 wt. \%; Aldrich Chemical Co.) were mixed in a 1:2 molar ratio, respectively. Deionized water was added as the diluent and sodium carbonate (99.5\%; Aldrich Chemical Co.) as the base catalyst in accordance with previous formulations [8]. In a glass reaction kettle, 1.2 liters of cyclohexane and 4.0 grams of surfactant (Sorbitan Monooleate; Sigma Chemical Co.) were stirred at approximately $350 \mathrm{rpm}$ using a variable speed mixer (Arrow 6000; Arrow Engineering Co., Inc.). Starting temperature of this solution varied between $25^{\circ} \mathrm{C}$ and $60^{\circ} \mathrm{C}$ depending on percent solids of the RF solution. Approximately $400 \mathrm{cc}$ of the RF solution was added to the cyclohexane/surfactant solution with constant stirring. The RF solution dispersed into spherical droplets throughout the cyclohexane---droplet size depended upon stir rate, method of addition, and surfactant ratio. After the inverse emulsion was heated for 2 to 8 hours, the agitation was stopped, spherical gel particles were allowed to settle, and the cyclohexane was decanted. The microspheres were then rinsed several times with acetone in preparation for supercritical drying from carbon dioxide $\left(T_{c}=31^{\circ} \mathrm{C} ; \mathrm{P}_{c}=7.4 \mathrm{MPa}\right)$. The resultant microspheres were subsequently pyrolyzed in a tube furnace at $1050^{\circ} \mathrm{C}$ (Model \#54657-208-3P; Lindberg) to form carbon aerogel microspheres.

RF aerogel microspheres can be formed to near-net shapes using a polymer binder and a compression molding technique. Five grams of microspheres were homogeneously mixed with 0.35 grams of polymer binder (Miralite 126; Pierson \& Stevens Chemical Corp.) and poured into an aluminum mold (76mm dia. x 13mm deep) coated with mold release (Frekote 33; Frekote Inc.). Pressure (approximately $0.01 \mathrm{MPa}$ ) was applied to the upper male portion of the mold and it was placed in an oven at $135^{\circ} \mathrm{C}$ for 5-12 hours. The resultant RF aerogel composites could then be pyrolyzed at $1050^{\circ} \mathrm{C}$ to form a carbon aerogel composite.

The morphology of both the RF aerogel microspheres and the carbon aerogel microspheres were examined using a Hitachi S-800 or S-4500 scanning electron microscope (SEM). The RF material was first coated with approximately $100 \AA$ of conducting carbon, platinum, or gold. The carbonized material required no special treatment and could be examined as submitted. The sample was placed on a SEM specimen stub using double sided carbon tape and placed in the instrument with a working distance of $15 \mathrm{~mm}$ to $30 \mathrm{~mm}$. After locating an area of interest, an appropriate magnification series of images were taken using Polaroid Polarpan 400 film.

Thermal conductivity was performed using a hot-wire apparatus [10]. The powder was placed in a cylindrical teflon powder cell $(20-50 \mathrm{~mm}$ dia.) which could be isostatically compressed and evacuated. A platinum wire, placed on the axis of the cell, served as both a heating element and temperature sensor. Voltage probes were attached to the ends of this wire and the data were used to extract the thermal conductivity under ambient conditions and as a function of gas pressure. RF composites were tested in a similar manner with the exception that the platinum wire was placed between two pieces of material.

Acoustic testing was performed under ambient conditions using a pulse transmission technique. The composite disk was placed between two identical transducers having a center frequency of $2.25 \mathrm{MHz}$. A digital oscilloscope, with an averaging function to improve the signal to noise ratio, was used to measure the traveling time of the sound signal through the sample $(\Delta t)$. Sound velocity $\left(c_{l}\right)$ was derived by dividing the part thickness by this measured time. The elastic modulus was then calculated using the following equation:

$$
\mathrm{C}_{11}=\rho * \mathrm{c}_{l}^{2}
$$

where $C_{11}$ is the elastic modulus and $\rho$ is the density of the microsphere/binder composite. 


\section{RESULTS AND DISCUSSION}

The formation of aerogel microspheres is a very attractive alternative for commercial manufacture of this low density porous material. Synthesis time is lessened, expensive processing equipment is virtually unnecessary, and the ability to compression mold the microspheres with a polymer binder into various molds are all cost effective. More importantly, however, is how the thermal and acoustical properties of aerogel microspheres compare to their monolith counterparts. Thermal conductivity and shear modulus have been performed on aerogel monoliths, loosely packed aerogel microspheres, and aerogel microsphere/polymer binder composites. The following discussion addresses these questions.

Thermal conductivity of loosely packed aerogel microspheres can be estimated using the following equation:

$$
\lambda_{\text {total }}=\lambda_{\text {aerogel }} \varphi \text { aerogel }+\lambda_{\text {air }} \varphi \text { air }
$$

where $\lambda$ is the thermal conductivity and $\varphi$ is the volume fraction of the respective phases. Using Eq.(2), the thermal conductivity of loosely-packed microspheres (without binder) would be expected to be $0.017 \mathrm{~W} / \mathrm{m} \cdot \mathrm{K}$. However, recent measurements on loosely packed RF aerogel microspheres, at a bulk density of $0.11 \mathrm{~g} / \mathrm{cm}^{3}$, gave a thermal conductivity of $0.019 \mathrm{~W} / \mathrm{m} \cdot \mathrm{K}$. This higher-than-predicted value is probably due to inhomogeneous packing and large interstitial voids between the microspheres. Never-the-less, the thermal conductivity is still below that of air $(0.024$ $\mathrm{W} / \mathrm{m} \cdot \mathrm{K}$ ). Further improvements can be made by selecting spheres having an appropriate mixture of diameters to achieve maximum packing efficiency, giving thermal conductivity values that approach that of the monolith.

Aerogel microspheres are potentially attractive for the formation of new low-density composites. For example, by adding the thermal conductivity and the volume fraction of the polymer binder into Eq.(2), the thermal conductivity of a composite is given by the following equation:

$$
\lambda \text { total }=\lambda \text { aerogel } \varphi \text { aerogel }+\lambda \text { polymer } \varphi \text { polymer }+\lambda \text { air } \varphi \text { air },
$$

Because of the gaseous conductivity in the interstitial voids between the aerogel micropsheres, a composite aerogel will never achieve as low a thermal conductivity as a monolith $(0.012 \mathrm{~W} / \mathrm{m} \cdot \mathrm{K})$. However, even with $10 \%$ binder, the aerogel composite is still able to achieve a thermal conductivity less than air. Figure 1 shows the thermal conductivity of RF microspheres as a function of the volume fraction of interstitial air and polymer binder.

Figure 1. A plot of total thermal conductivity vs volume fraction of air or polystyrene binder in an aerogel composite formed from resorcinol-formaldehyde microspheres. The individual microspheres are assumed to have a density of $0.16 \mathrm{~g} / \mathrm{cm}^{3}$ and $\lambda=0.012 \mathrm{~W} / \mathrm{m} \cdot \mathrm{K}$. 
Figure 2a shows a SEM of the microsphere composites. The aerogel microspheres are tacked together by the string-like webbing of the polymer binder which was a thin-walled polymer shell containing a blowing agent prior to the compression molding process. Following pyrolysis (Figure 2b), the polymer binder seems almost non-existent with traces of shells left on the surfaces of the microspheres. Though the amount of polymer binder has been reduced through carbonization, the shape and integrity of the composite appear unchanged.

Figure 2. Scanning electron micrographs of compression molded (a) RF microspheres and polymer binder and (b) carbonized composite.

The elastic moduli of the RF and carbon composites as compared to their monolithic counterparts are shown in Figure 3. While the $0.2 \mathrm{~g} / \mathrm{cc}$ RF monolith has a modulus of $4.5 \mathrm{MPa}$, the RF composite of the same approximate density of $0.19 \mathrm{~g} / \mathrm{cc}$, has a modulus of $10 \mathrm{MPa}$ indicating the positive effect of the polymer binder. The moduli for both the carbon composite and the carbon monolith are approximately the same due to the elimination of the binder during pyrolysis. Additional samples at varying densities and a more consistent compression molding technique will provide data for a more complete acoustical study.

Figure 3. Elastic moduli of both RF and carbon microsphere composites as compared to their respective monoliths. 
Resorcinol-formaldehyde and carbon aerogel microspheres have the potential for many applications. RF microspheres may be blended with polymer binders to form a new type of thermal insulation. Carbon microspheres have found applications in supercapacitor electrodes. Other potential applications include gas storage (e.g., hydrogen, methane), chromatographic packings, and ion-exchange resins. The formation of aerogel microspheres will simultaneously increase the number of potential applications and decrease the cost of production.

\section{SUMMARY}

Aerogels are a special class of porous materials composed of interconnected particles and pores with nanometer-sized dimensions. This unique structure is responsible for the low thermal conductivity values caused by the suppression of gaseous conduction and convection. Monolithic resorcinol-formaldehyde aerogels have been studied at LLNL nearly a decade. Current processing methods have limited the introduction of monolithic aerogels into the commercial marketplace. However, an inverse emulsion polymerization can be used to produce a more amenable form of aerogels--microspheres. Thermal conductivity measurements of both the loosely packed powders and the microsphere/binder composites have shown values slightly higher than their monolithic counterparts, but lower than air. Elastic modulus measurements demonstrate a slight increase for RF composites over monoliths while carbon composites showed a slight decrease. The production of resorcinol-formaldehyde aerogel microspheres will aid in the elimination of current processing restrictions without sacrificing the unique thermal and mechanical properties of their monolithic counterparts.

\section{ACKNOWLEDGMENTS}

This work was performed under the auspices of the U.S. Department of Energy by Lawrence Livermore National Laboratory under contract \#W-7405-ENG-48. The author would like to thank Jim Yoshiyama for providing SEMs. A special thanks to Dr. Rick Pekala for his dedication to this project and the advancement of the primary author's career.

\section{REFERENCES}

[1] . R.W. Pekala and C.T. Alviso, Mater. Res. Soc. Symp. Proc., 180, 791 (1990).

[2] R.W. Pekala, J. Mater. Sci., 24, 3221 (1989).

[3] R.W. Pekala and F.M. Kong, J. Phys. Coll. Suppl., 50(4), C4-33 (1989).

[4] R.W. Pekala and F.M. Kong, Polym. Prpts., 30(1), 221 (1989).

[5] R.W. Pekala and C.T. Alviso, in Novel Forms of Carbon, C.L. Renschler, J.J. Pouch, and D.M. Cox, eds., MRS Symp. Proc. 270, 3 (1992).

[6] R.W. Pekala, C.T. Alviso, and J.D. LeMay, in Chemical Processing of Advanced Materials, L.L. Hench and J.K. West, eds., (New York: John Wiley \& Sons, Inc., 1992), pp. 671-683.

[7] R.W. Pekala, C.T. Alviso, F.M. Kong, and L.W. Hrubesh, Organic Aerogel Microspheres, C\&MS Annual Report

[8] R.W. Pekala, C.T. Alviso, X. Lu, R. Caps, and J. Fricke, Am. Chem. Soc. Proc., (1995).

[9] X. Lu, M.C. Arduini-Schuster, J. Kuhn, O. Nilsson, J. Fricke, and R.W. Pekala, "Thermal Conductivity of Monolithic Organic Aerogels," Science, 255, 971 (1992).

[10] O. Nilsson, G. Ruschenpohler, J. Gross, and J. Fricke, High Temp.-High Pressures, 21, 267 (1989). 
Figure 1.
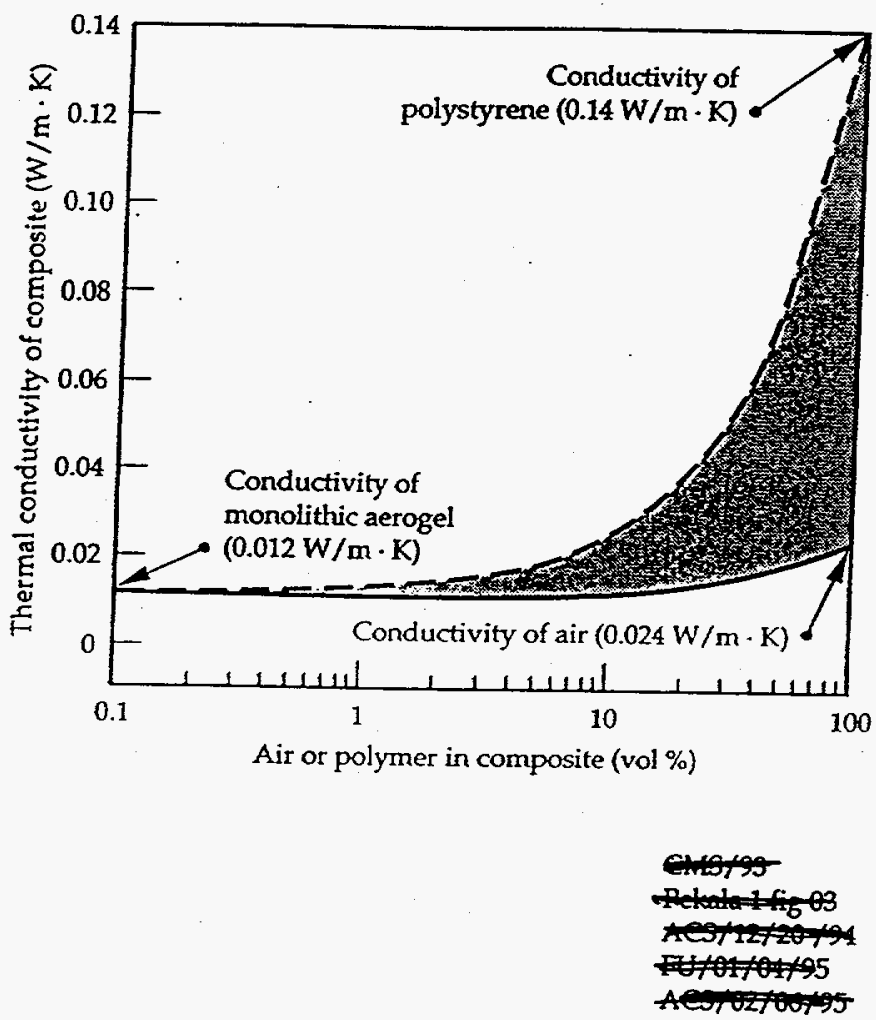
Figure 2.

(b)

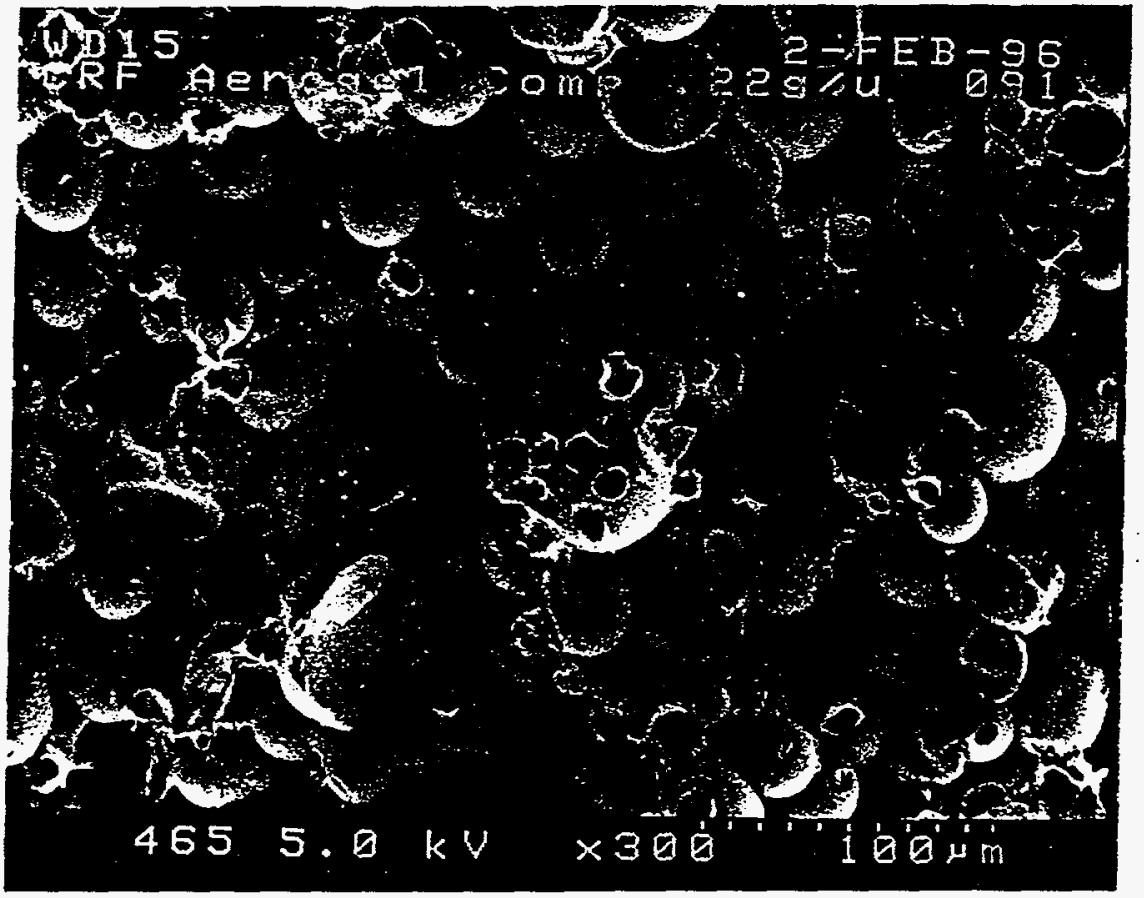

(a)

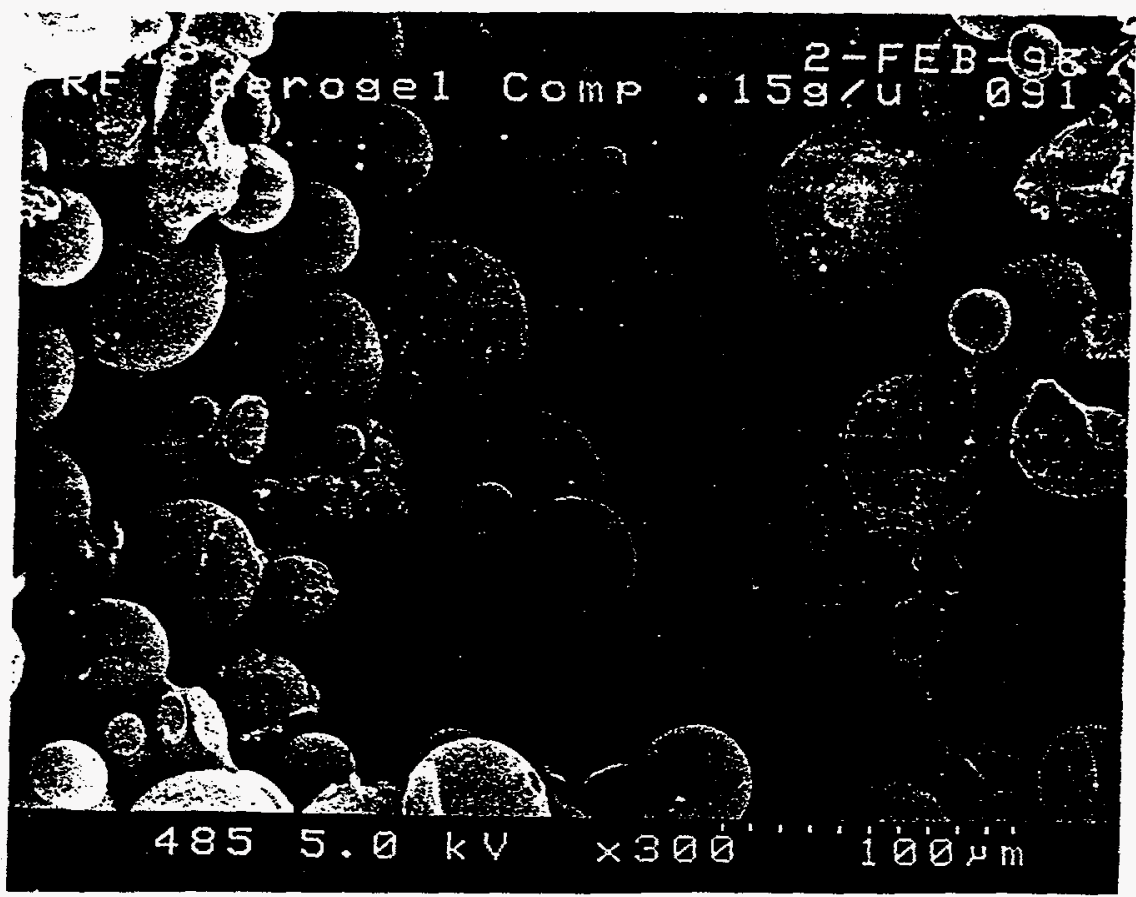




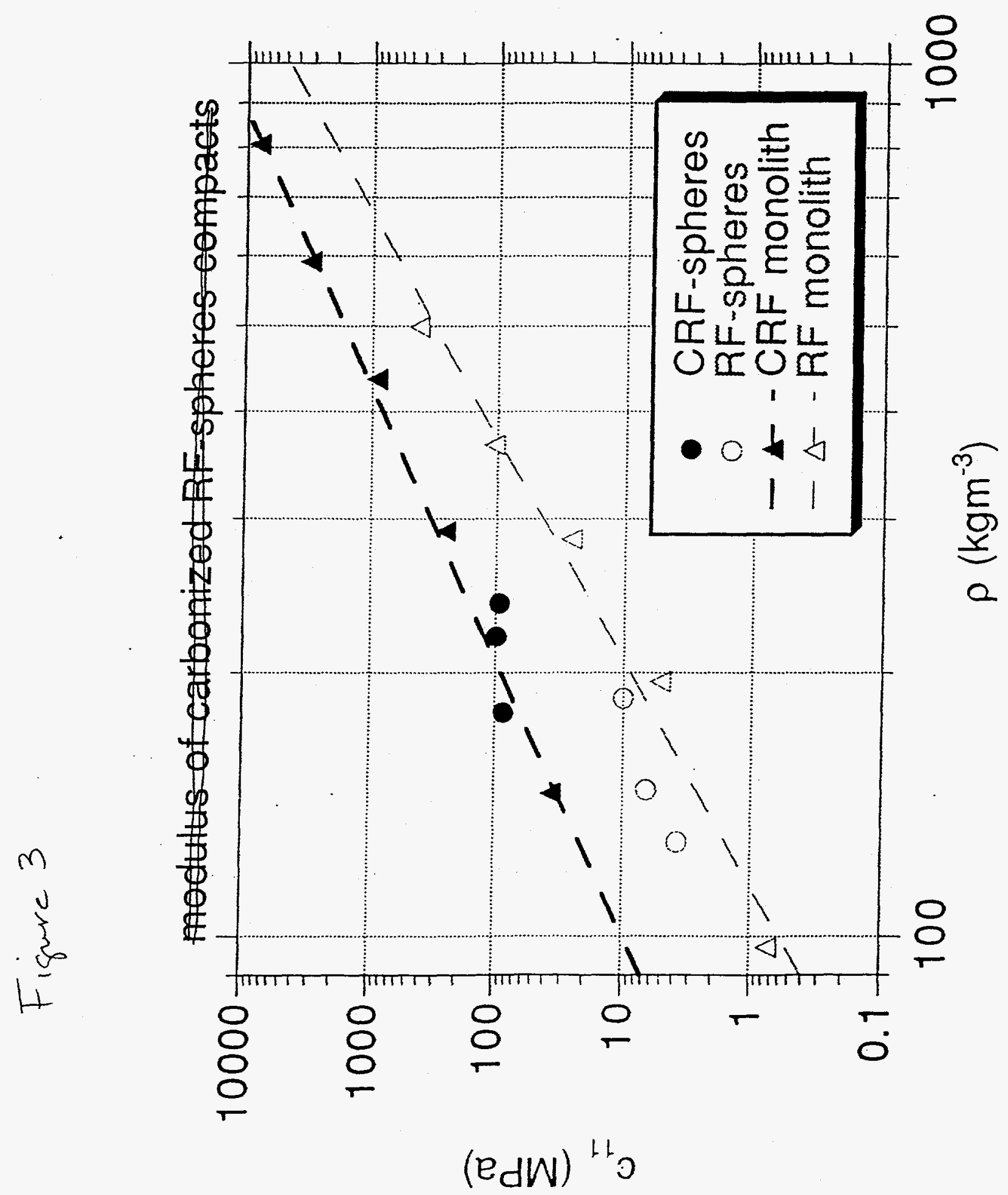

